\title{
A conversação sobre temas políticos em contextos comunicativos do cotidiano
}

\author{
Ângela Cristina Salgueiro Marques* \\ Rousiley Celi Moreira Maia**
}

\section{Introdução}

E studos desenvolvidos por pesquisadores - notadamente das áreas de Ciência Política, Filosofia Política e Comunicação Social - têm demonstrado especial interesse pelo papel que as interações comunicativas desempenham em contextos em que os indivíduos buscam desenvolver, rotineiramente, capacidades e habilidades vinculadas à participação política e à construção da cidadania (GAMSON, 1992; HABERMAS, 1997; MANSBRIDGE, 1999; SCHEUFELE, 2000; WYATT, KATZ \& KIM, 2000; CONOVER, SEARING \& CREWE, 2002). Esses trabalhos mostram que formas específicas de interação discursiva, como a conversação e a discussão, são essenciais para a

* Ângela Cristina Salgueiro Marques é Doutora em Comunicação Social pela UFMG. Atualmente, realiza um estágio pós-doutoral no Groupe de Recherche sur les Enjeux de la Communication (Gresec), na Université Stendhal Grenoble III (França). Atua também como pesquisadora do Grupo de Pesquisa sobre Mídia e Esfera Pública (EME) do Programa de Pós-Graduação em Comunicação Social da UFMG. Endereço eletrônico: angelasalgueiro@gmail.com.

*** Rousiley Celi Moreira Maia é Professora Adjunta do Departamento de Comunicação Social da UFMG, Doutora em Ciência Política pela University of Nottingham (Inglaterra) e Coordenadora do Grupo de Pesquisa sobre Mídia e Esfera Pública (EME) do Programa de Pós-Graduação em Comunicação Social da UFMG. Endereço eletrônico: rousiley@fafich.ufmg.br.

1 Este trabalho foi realizado com o apoio da Coordenação de Aperfeiçoamento de Pessoal de Nível Superior (Capes). Agradecemos as contribuições e observações feitas pelo Professor Wilson Gomes e pelos pesquisadores do Grupo de Pesquisa sobre Mídia e Esfera Pública (EME) da Universidade Federal de Minas Gerais (UFMG) à primeira versão do texto, especialmente a Ricardo Mendonça, Hellen Castro e Dilvan Azevedo. 
criação de modos mais complexos de entendimento de situações, políticas públicas, programas ou questões problemáticas relativas à vida cotidiana dos cidadãos. Tais estudos, contudo, ao procurarem evidenciar as contribuições da discussão política ou da conversação cotidiana à democracia deliberativa, não exploram a dinâmica das trocas comunicativas que se dão entre parceiros dialógicos localizados em esferas de maior invisibilidade social com a devida atenção. O foco ainda persiste nos discursos que compõem o fluxo principal (mainstream) das questões de ampla publicidade.

Vários autores evidenciam que as capacidades cognitivas e críticas, além das oportunidades participativas, necessárias à deliberação política em esferas públicas são restritas a grupos e indivíduos desfavorecidos com relação a questões de gênero, classe social, idade e raça (FRASER, 1992; BOHMAN, 1996; YOUNG, 1996). Nesse sentido, as mulheres, os pobres e as pessoas idosas demonstrariam preferência por estabelecer conversações em espaços protegidos e privados, de modo que se identificassem conflitos e melhor se entendessem suas necessidades (CONOVER, SEARING \& CREWE, 2002). Esses indivíduos, justamente por não conseguirem enviar suas demandas a espectros mais visíveis da esfera principal de debate, são considerados, de antemão, inaptos às atividades políticas e, portanto, incapazes de construir um tipo de autonomia que os permita ser considerados igualmente capazes de formular, expressar e defender seus argumentos diante dos outros (MARQUES \& MAIA, 2007).

Ao partirmos dessa premissa, tínhamos como propósito investigar o modo como mulheres pobres produzem sentido coletivamente acerca de questões políticas sobre as quais, supostamente, teriam pouca informação. Se, a princípio, as conversações travadas em contextos rotineiros de interação são apontadas como atividades essenciais para a formulação e o aprimoramento de atitudes democráticas e cívicas, seria possível esperar um comportamento crítico e reflexivo dessas mulheres? Em que contextos elas teriam oportunidades de desenvolver conjuntamente seus interesses e chegar a entendimentos acerca de temas políticos que as afetam diretamente? Instigou-nos, ainda, investir em uma pesquisa empírica que reunisse mulheres que, além de pobres, fossem beneficiárias de 
políticas sociais de transferência de renda, como o Programa BolsaFamília $^{2}$. A nosso ver, além de inaptas para a política, essas mulheres também são consideradas "inúteis" para a produção econômica, uma vez que não trabalham (PAUGAM, 1993; TELLES, 1999).

Diante do quadro acima esboçado, realizamos grupos de discussão em duas cidades da Região Sudeste do Brasil - Belo Horizonte (MG) e Campinas (SP) -, nas quais o Programa Bolsa-Família encontra-se em diferentes estágios de implementação. Neste artigo, nosso interesse está menos na realização de uma análise do referido Programa do que no entendimento da dinâmica da troca discursiva na qual as beneficiárias, reunidas em espaços que frequientam rotineiramente, estabelecem momentos em que a conversação sobre temas rotineiros e dramas pessoais dão lugar à atividade crítica de defesa de posições e identificação de divergências que são assumidas ou silenciadas. Buscamos explorar, em particular, o modo pelo qual essas características da troca dialógica apresentam importantes contribuições para os processos democráticos de formação de cidadãos autônomos e aptos a tematizarem suas questões em esferas públicas deliberativas mais amplas.

Este artigo está estruturado em três partes: na primeira, recuperamos as discussões entre diferentes autores a respeito da distinção entre as noções de "conversação política" e "discussão política” e suas respectivas contribuições e obstáculos à deliberação pública. Na segunda, exploramos a metodologia de grupos de discussão como um instrumento capaz de revelar de que maneira as conversações em contextos cotidianos e as discussões políticas

2 Criado em outubro de 2003, o Bolsa-Família representa hoje o principal sustentáculo da política social do atual governo. Seus técnicos e idealizadores apontam que o Programa foi concebido para atuar em duas frentes: distribuição de recursos àqueles em situação de extrema pobreza e, num segundo passo, incentivo à implementação municipal de alternativas emancipatórias ligadas às condicionalidades do Programa, como cursos profissionalizantes, de alfabetização, manter as crianças na escola, motivar visitas aos postos de saúde, incentivar a agricultura familiar etc. Não ignoramos que cada município brasileiro possui modos distintos e dificuldades próprias de implementação dessas alternativas, o que faz com que existam poucas experiências caracterizadas como bem-sucedidas e muitos casos de fraudes e desvio de verbas. Para mais detalhes acerca desse Programa, ver: http://www.mds.gov.br/bolsafamilia. 
imbricam-se, trazendo ganhos ao amplo processo deliberativo, e focalizamos as formas de interação e de trocas comunicativas presentes nos grupos de discussão sobre o Bolsa-Família realizados com beneficiárias. E, na terceira parte, apresentamos trechos das conversações e discussões obtidas nos grupos, a fim de analisarmos os momentos de politização construídos pelos participantes.

\section{As conversações e as discussões políticas no sistema deliberativo}

A teoria deliberativa tem conferido especial interesse aos "contextos de descoberta" nos quais são desenvolvidas discussões políticas destinadas a "captar novos problemas, conduzir discursos expressivos de auto-entendimento e de articular, de modo mais livre, identidades coletivas e interpretações de necessidades" (HABERMAS, 1997). Nesses contextos, sobressaem-se as conversações políticas ordinárias constituídas por uma mistura entre questões políticas, eventos mais prosaicos e experiências pessoais, aproximando público e privado (WYATT, KATZ \& KIM, 2000). Entretanto, alguns autores apontam que as conversações em contextos do cotidiano não podem ser confundidas com as discussões políticas deliberativas (SCHUDSON, 1997; GUTMANN \& THOMPSON, 1999; SEARING et alii, 2004; MOY \& GASTIL, 2006). Para eles, somente essas últimas seriam capazes de trazer contribuições para os processos democráticos.

Nessa perspectiva, vários autores buscam evidenciar as diferenças existentes entre os papéis desempenhados pela conversação cotidiana e pela discussão política ${ }^{3}$. A maioria deles enfatiza que so-

3 Soma-se a isso uma grande confusão terminológica entre as expressões de língua inglesa: everyday talk, political talk, political conversation e political discussion. Gregory Streich (2002), por exemplo, aponta que political talk e political discussion são utilizadas como sinônimos. Para ele, a expressão everyday talk indica um vasto campo que abrange uma diversidade de formas discursivas de entendimento e tratamento de questões de natureza política, social e cultural. Assim, a deliberação, a conversação política e a discussão política fariam parte desse campo juntamente com outras formas de comunicação, como o testemunho, os gestos e a retórica (cf. também YOUNG, 1996, p. 120-136; DRYZEK, 2000; BURKHALTER et alii, 2002). 
mente esferas discursivas voltadas para a discussão política poderiam ser úteis ao processo deliberativo. Segundo James Bohman (1996, p. 34), a conversação, por ter um caráter privado, não ofereceria as condições de inclusão e publicidade requeridas pela deliberação. Para James Fearon (1998, p. 63), “a deliberação se refere a um tipo particular de discussão, que envolve cuidado e séria consideração de razões a favor e contra alguma proposição". Contrariamente, uma discussão comum não precisa ser cuidadosa, séria, racional, guiada por normas e voltada para um objetivo comum.

A contraposição entre um tipo de "conversação sociável", voltada à criação de vínculos de sociabilidade entre pessoas que pensam de modo semelhante, e uma "conversação voltada para a solução de problemas" está na base da argumentação de Michael Schudson (1997). Segundo ele, a conversação cotidiana ocorreria entre conhecidos, não estaria ligada a uma agenda nem seria constrangida por normas formais de expressão. Ela se ocuparia de temas que versam sobre experiências pessoais, tradições culturais, crenças compartilhadas e modos de relacionamento e percepção. Já a discussão política seria pautada por uma agenda, encontrar-se-ia submetida a regras que constrangem formas rudes e ofensivas de expressão e, ainda, voltar-se-ia para a busca de soluções. A discussão política, em particular, é vista como a troca racional de argumentos entre cidadãos igualmente interessados e informados. Teria como foco as dinâmicas de tomada de decisão, os processos eleitorais e de participação do cidadão na elaboração de normas e direitos. Schudson opera com a premissa de que os cidadãos, a fim de exercitarem a discussão política, precisam estar bem informados, reunir-se regularmente para refletir e buscar solucionar conflitos, decidir as prioridades de políticas públicas e questionar-se sobre suas escolhas eleitorais.

As proposições de Schudson foram amplamente criticadas. Diferentes autores (GAMSON, 1992; SCHEUFELE, 2000; WYATT, KATS \& KIM, 2000; CONOVER, SEARING \& CREWE, 2002; STREICH, 2002; SEARING et alii, 2004) sustentam que a conversação política que ocorre em diferentes contextos cotidianos pode trazer importantes contribuições para processos deliberativos. Para Jane Mansbridge (1999, p. 211), a conversação cotidiana, ao 
proporcionar oportunidades para que as pessoas explicitem, negociem e justifiquem suas necessidades e projetos, pode auxiliá-las a entender melhor o que querem e o que precisam, individual e coletivamente. $\mathrm{O}$ contexto comunicativo formado por meio dessa conversação é geralmente marcado pela afirmação e renovação de quadros compartilhados de valores, incluindo, também, é claro, a reprodução de preconceitos e desigualdades.

Determinadas conversações em contextos cotidianos, entretanto, podem desafiar regras estigmatizantes, ao deslocar experiências negativas de contextos privados para espaços coletivos de debate, nos quais as pessoas compartilham informações e constroem conjuntamente o conhecimento. Por exemplo, experiências de violência doméstica, machismo ou preconceito racial, ao se transformarem em tópico principal de conexão de múltiplos contextos de conversação, podem ajudar na contestação de regras ou discursos tidos como não-problemáticos ou incontestáveis (VAN DIJK, 1999; MAIA \& MARQUES, 2002).

As pessoas, ao conversar e trocar pontos de vista umas com as outras, podem melhorar formas de pensar e de interpretar questões políticas que afetam diretamente suas vidas, e, ainda, aperfeiçoar os modos de formular verbalmente questões tidas como relevantes. Esse é o primeiro passo para a tematização e a negociação pública de interesses. Como alguns autores já apontaram (BOHMAN, 1996; PORTO, 1998; NORRIS, 2000; MAIA, 2004), o dilema democrático não se resume à posse de informações, mas estende-se a processos de construção discursiva do conhecimento, em que os participantes devem demonstrar capacidades comunicativas para engajar-se na troca argumentativa com outras pessoas ou outros grupos sociais que apresentam opiniões ou crenças divergentes.

Searing et alii (2004) reconhecem que o exercício da deliberação é muito mais rigoroso do que as discussões informais sobre questões de interesse público. Eles seguem, contudo, a abordagem assumida por Mansbridge, ao afirmarem que a conversação política cotidiana, apesar de possuir uma qualidade deliberativa fraca e de frequientemente dispersar-se por assuntos variados, parece produzir algumas consequiências desejáveis para a forma- 
ção de cidadãos autônomos, informados e críticos. Curiosamente, essas são as consequiências atribuídas, muitas vezes, às práticas mais rigorosas de deliberação.

Para lidar com essa questão, Amy Gutmann e Denis Thompson (1999) estabelecem dois tipos distintos, porém complementares, de interação comunicativa: uma conversação cotidiana estabelecida em contextos mais restritos e voltada para assuntos de interesse humano e danos morais, físicos ou afetivos; e uma discussão política essencialmente voltada para processos de troca argumentativa, para a apreciação de cursos alternativos de tomada de decisão e para a busca de fins coletivos. Eles apontam que as conversações em contextos interativos do cotidiano envolvem particularmente o desafio a regras e concepções que acarretam danos morais e éticos aos sujeitos e grupos. Segundo eles, o processamento do desacordo moral nas conversações travadas em contextos cotidianos alimenta os debates políticos que acontecem em esferas políticas formais, confrontando perspectivas e interesses privados com questões e demandas coletivas. Gutmann e Thompson (1999, p. 274) fazem, contudo, a ressalva de que nem todo tipo de conversação cotidiana é capaz de promover esses deslocamentos, mas somente aquela que estiver "intencionalmente dirigida para questões que o público deva discutir e possivelmente agir sobre elas”. Nas esferas políticas formais, os participantes, na maioria das vezes, sentem-se constrangidos a articular seus pontos de vista levando em consideração interesses coletivos, publicamente defensáveis.

Esses diferentes autores, entretanto, concordam em um ponto: a divisão entre conversação cotidiana e discussão política não pode ser entendida como uma dicotomização simplista, pois ambas são formas complementares e intersectantes de extrema importância para os processos democráticos de participação, socialização política e entendimento de problemas coletivos. A conversação e a discussão política sobre temas e assuntos publicamente relevantes exigem que os parceiros dialógicos construam seus pontos de vista e sejam capazes de explicá-los e defendê-los ao se depararem com indagações alheias. É principalmente o conflito e o desacordo moral, e as estratégias de sua explicitação, que marcam o que há 
de comum entre conversações políticas em espaços cotidianos e discussões políticas. Nesse sentido, boa parte das pesquisas empíricas ligadas à deliberação revela o potencial das conversações do cotidiano para a construção de direitos e de maneiras diversas de participação política (MANSBRIDGE, 1999; WYATT, KATZ \& KIM, 1999; 2000; BENNETT, FLICKINGER \& RHINE, 2000; MUTZ \& MARTIN, 2001; WEST \& GASTIL, 2004; MOY \& GASTIL, 2006).

É o quadro teórico acima delineado que nos motiva a investigar empiricamente como a conversação cotidiana e a discussão política podem estar imbricadas. Mas como captar essas conversas e discussões? E ainda: como captar os momentos em que um fluxo conversacional sobre assuntos diversos atinge situações de tomada de posição e de expressão de pontos de vista contrários? Essa é uma tarefa particularmente difícil por três motivos principais: a) estudos ressaltam que a discussão política informal é pouco propícia à expressão de desacordos (CONOVER, SEARING \& CREWE, 2002; DUCHESNE \& HAEGEL, 2004); b) pesquisas empíricas sobre conversações e discussões políticas raramente são realizadas em contextos rotineiros de circulação e vivência dos cidadãos comuns, uma vez que a maior parte delas concentra-se em fóruns deliberativos formais, reuniões e assembléias locais; c) o tratamento dos dados obtidos após a realização dos grupos de discussão focaliza-se frequientemente em registrar expressões específicas ou padrões de respostas, ao invés de elaborar uma análise das dinâmicas interativas, dos constrangimentos contextuais, e dos diferentes discursos acionados pelos participantes para a construção do próprio posicionamento (KITZINGER, 1994; MORGAN, 1997; MEYERS, 1998).

A solução por nós encontrada foi organizar e realizar grupos de discussão ${ }^{4}$, uma vez que o contexto desses grupos permite

4 O uso do termo "grupos de discussão" difere da concepção usualmente associada ao termo "grupos focais", ou seja, a uma perspectiva ligada a pesquisas de marketing ou modos de consumo em que pouco interesse é conferido à dinâmica intersubjetiva estabelecida entre os participantes. Apesar de adotarem o termo "grupos focais", a maioria dos pesquisadores que empregam esse método nas Ciências Sociais confere especial destaque à importância de se observar o modo coletivo de construção dos discursos e não sua mera expressão individual (BERTRAND, BROWN \& WARD, 1992; KITZINGER, 1994; LETELIER, 1996; MORGAN, 1996; SMITHSON, 2000; DUCHESNE \& HAEGEL, 2004; WARR, 2005). 
que os participantes articulem experiências e dramas privados a questões de natureza coletiva, ou seja, problemas relacionados a políticas sociais, a leis, aos direitos e à própria política institucional. Argumentamos que, nos contextos comunicativos dos grupos de discussão, muitos conflitos potenciais encontram-se dissolvidos no curso de uma conversação em que as frases e as idéias se sucedem sem serem postas em conexão. Entretanto, há momentos em que os participantes passam não só a expressar publicamente suas opiniões sobre um dado tema político, mas também a defendê-las e a revisá-las diante do questionamento alheio. Em tais momentos de politização, os cidadãos passam a discutir sobre questões de interesse público, a construir preferências, a refletir sobre o bem comum, subsidiando a formação da opinião e da vontade.

Levando em conta essas observações, nosso intuito fundamental é o de evidenciar que as trocas comunicativas estabelecidas entre as mulheres beneficiadas pelo Bolsa-Família são constituídas por uma mistura de sequiências de conversações informais ordinárias e de discussões políticas que, mesmo não tendo um caráter deliberativo em si, constituem uma peça central do amplo processo deliberativo. Instiga-nos explorar como tais mulheres, ainda que precariamente munidas de recursos materiais e políticos, elaboram seus próprios discursos e, assim, procuram entender e produzir sentido acerca dos diferentes discursos que lhes dizem respeito. Na próxima seção, caracterizaremos o grupo de discussão enquanto um método que agrega diferentes formas de discussão interpessoal, como a conversação cotidiana e o discurso político, dependendo do conteúdo em debate, da forma como os participantes se expressam e se posicionam reciprocamente.

\section{A dinâmica comunicativa no contexto de grupos de discussão}

Neste artigo, optamos por utilizar a noção de "grupos de discussão", entendendo-os como contextos discursivos controlados de conversações e discussões capazes de estimular as conversações do cotidiano e de oferecer oportunidades de politização das trocas comunicativas de modo a gerar situações de indagação mútua 
acerca de temas sociais e políticos ${ }^{5}$. A nosso ver, esses momentos de politização revelam elementos ligados ao processo de discussão política, uma vez que se originam da tensão estabelecida entre os participantes e entre estes e o moderador, na medida em que têm a possibilidade de envolverem-se em interações comunicativas voltadas para: a) a (re)construção e contestação de sentidos; b) o modo como os participantes, localizados em um contexto sociocultural específico, fazem perguntas uns aos outros e explicam suas posições reciprocamente; c) a explicação das premissas por trás de seu pensamento e d) a indagação a respeito das ações e opções próprias e alheias (CAREY, 1994; KITZINGER, 1994; MORGAN, 1996; BRYMAN, 2001; WARR, 2005). Nessa vertente, Jenny Kitzinger (1994, p. 106) aponta que os grupos de discussão oferecem a oportunidade de criação de contextos interativos que podem ser entendidos como fóruns em que as idéias podem ser esclarecidas, estimulando as pessoas a "se engajarem umas com as outras, a formularem verbalmente suas idéias e exporem as estruturas cognitivas que estavam previamente desarticuladas".

Considerando a abordagem acima explicitada, organizamos oito grupos de discussão com as beneficiárias do Bolsa-Família, quatro em Belo Horizonte e quatro em Campinas ${ }^{6}$. Na época da

5 Lunt e Livingstone (1996) apontam que o contexto interativo de grupo é capaz de constituir-se em um contexto propício à reprodução ou recriação do tipo de conversação que as pessoas desenvolvem em seus contextos cotidianos de interação. Devemos sempre ter em mente, contudo, que um grupo de discussão é um contexto de interação comunicativa artificialmente construído. Não podemos, portanto, criar a expectativa de que os participantes do grupo se comportem da mesma forma que em seus ambientes relacionais rotineiros, uma vez que existem inúmeras variáveis que podem criar constrangimentos aos participantes do grupo, sobretudo as relações de poder que se estabelecem entre moderador/ participantes e entre os próprios participantes. Cabe ao moderador propor os temas do debate, mas com a consciência de que são os participantes que o conduzem, posicionando-se em relação aos tópicos propostos pelo pesquisador.

6 As beneficiárias, com idades que variam de 27 a 60 anos, foram selecionadas com o auxílio das Coordenadorias Regionais de Assistência Social (CRAS) correspondentes a cada região. Os grupos foram compostos de três a oito mulheres cadastradas no Programa Bolsa-Família, independentemente de critérios como valor do benefício recebido, idade, raça e classe social. Foram escolhidas mulheres porque o Programa concebe-as como as verdadeiras "administradoras do lar", além disso o cartão do Programa é feito no nome da mulher. 
realização da pesquisa de campo, as duas cidades encontravam-se em estágios diferenciados de implementação do Programa ${ }^{7}$. Foi possível comprovar que a cidade de Belo Horizonte, além de contar com um alto grau de organização dos dados cadastrais e conhecimento das beneficiárias ${ }^{8}$, possuía mais condições de mobilizar as redes de assistência social responsáveis pelo atendimento às famílias no que se refere à realização de cursos profissionalizantes, oficinas, projetos integrados de cooperativas etc. Além disso, as ações vinculadas ao Programa já se encontravam descentralizas e sob a responsabilidade das nove administrações regionais da cidade. Já a cidade de Campinas passava pela etapa de implantação do Programa. Nessa cidade, a maior parte do processo ainda era monitorada pela Secretaria de Assistência Social, que, por não possuir um banco de dados unificado, tinha grandes dificuldades de planejar ações com as beneficiárias. Tal disparidade motivou-nos a detectar nas duas cidades a relação que as beneficiárias mantinham com o Programa, ainda que, neste artigo, não tenhamos explorado tal questão.

O contato com as beneficiárias foi feito por telefone; os números foram obtidos previamente nos Núcleos de Apoio à Família (NAF), em Belo Horizonte, e nos Centros de Referência da Assistência Social (CRAS), em Campinas. Ao selecionarmos as participantes com base nos cadastros dispostos por esses equipamentos da Prefeitura Municipal, tínhamos em mente reunir mulheres que frequientavam rotineiramente esses locais, participando ativamente ou não de cursos, oficinas e cooperativas disponibilizadas por essas instituições. Preocupava-nos, primeiro, em não isolá-las de seus espaços rotineiros de circulação e convivência e, segundo, em perceber como se dava sua inserção em espaços formais e administrativos do município.

O roteiro para a discussão nos grupos de discussão foi organizado em torno de questões semi-estruturadas de modo a permitir

7 A pesquisa de campo foi realizada entre outubro de 2005 e agosto de 2006.

8 O mapeamento das áreas de vulnerabilidade social da capital mineira e um acompanhamento das famílias aí residentes já vinham sendo realizados desde o ano de 2001 pela prefeitura. Em 2002, essas atividades passaram a integrar o Projeto BH Cidadania. 
que as beneficiárias respondessem a questões referentes à sua própria experiência com o Programa ${ }^{9}$.

Com relação à apresentação e ao tratamento dos dados obtidos por nós, optamos por tomar as seguintes medidas: a) os nomes dos participantes foram substituídos por nomes fictícios; b) ao final de cada discussão aqui transcrita, indicamos a região, a data em que o grupo foi realizado e a cidade dos participantes. O modo escolhido para o registro das falas durante a realização dos grupos foi a gravação em fitas cassete.

\section{A construção coletiva do sentido acerca de questões políticas}

Segundo Deborah Warr (2005), Kitzinger e Farquhar (1999), a natureza da conversação gerada nos grupos de discussão é uma mistura de crenças pessoais e narrativas coletivas disponíveis, sendo que é preciso identificar os momentos em que a expressão de pontos de vista divergentes sai de um estado latente para um posicionamento argumentativo explícito. A distinção entre essas duas formas de interação depende de dois esclarecimentos essenciais: a) o pesquisador deve definir a natureza da questão a ser tematizada no grupo; b) o pesquisador precisa definir os tipos de interação que se processam nos grupos por ele realizados. Geralmente, podemos identificar nos grupos de discussão os seguintes tipos de interação: a) complementares (voltadas para o acionamento de elementos do mundo social e da experiência subjetiva capazes de gerar um quadro

9 As questões referentes à primeira parte da dinâmica foram agrupadas em torno de três tópicos nucleadores: a) o entendimento que as beneficiárias têm do Programa - o objetivo desse tópico era investigar como elas definiam o Programa; b) as alternativas disponíveis para escapar da pobreza - esse tópico visava explorar as escolhas por elas elencadas para superar os obstáculos que impedem a construção da autonomia, pretendíamos investigar o valor que elas conferiam ao trabalho, à educação, à participação em projetos coletivos etc.; e c) a luta por direitos, reconhecimento e cidadania - a finalidade das perguntas elaboradas nesse tópico era a de analisar como essas noções apareciam no discurso das beneficiárias. O que vem a ser um direito para elas? Elas associam os direitos à sua independência e à sua valorização pelos outros? 
comum de entendimento entre os participantes); b) argumentativas (diferenças de opinião permitem aos participantes revisarem seus pontos de vista, refletindo sobre as razões que sustentam) (cf. KITZINGER, 1994; BRYMAN, 2001); e c) contradiscursivas (articulação de experiências e pontos de vista de modo que desafiem clichês, estereótipos opressores e construções culturais dominantes). E, dentro dessas formas interativas, encontramos formas significativas de comunicação como piadas, brincadeiras, contação de casos, gestos que influenciam na maneira como os participantes estabelecem vínculos uns com os outros e com o moderador.

Como já apontado, os contextos de trocas comunicativas proporcionadas pelos grupos de discussão dão a ver um fluxo desconexo entre experiências pessoais e temas políticos. Entendemos que a conexão entre essas diferentes referências discursivas ocorre quando a maior parte do grupo assume uma posição diante de um tópico de discussão. Muitas vezes, essa dinâmica envolve "momentos sensíveis" (KITZINGER \& FARQUHAR, 1999) de politização, ou seja, momentos em que "os interlocutores reconhecem, a propósito de uma questão de interesse coletivo, a existência de pontos de vista divergentes e aceitam o risco de entrar em desacordo explícito e assumido com seus interlocutores em nome de idéias, interesses ou valores" (DUCHESNE \& HAEGEL, 2004, p. 883-884). Muitas vezes, essas questões dizem respeito à identidade dos participantes dos grupos, despertam experiências de opressão e remetem às posições que ocupam na sociedade (CONOVER, SEARING \& CREWE, 2002; WARREN, 2006).

Nossa análise visa evidenciar esses momentos de politização, a tomada de posicionamentos e atitudes desencadeados por questões sensíveis e seus possíveis desdobramentos. Pretendemos destacar a importância que as conversações e discussões políticas trazem para o processo deliberativo no que tange a: a) produção de contranarrativas, b) revelação de premissas de fundo, c) identificação de questões sensíveis e d) opção de assumir ou não o risco do debate. 


\subsection{A produção de contranarrativas}

É sabido que os chamados "contrapúblicos subalternos"10 constituem-se como vozes minoritárias, invisíveis e algumas vezes opositoras. Tais públicos expressam-se fora do fluxo discursivo principal das esferas de visibilidade ampliada e dos espaços deliberativos formais. As esferas privadas de conversação e encontro fornecem o contexto para que esses públicos troquem impressões e articulem pontos de vista que desafiam os discursos públicos. Os espaços cotidianos frequientados pelos contrapúblicos são descritos por Nancy Fraser (1992, p. 123) como "arenas discursivas paralelas onde os membros de grupos subordinados inventam e circulam contradiscursos". A idéia de que ao lado de um discurso há sempre um contradiscurso não é nova (NEUMAN et alii, 1992; YOUNG, 1996). No caso de grupos marginalizados, os testemunhos acionados em contextos de conversação cotidiana funcionam como narrativas que desafiam e desestabilizam entendimentos ligados a discursos amplamente difundidos.

No contexto dos grupos de discussão realizados, o questionamento de preconceitos enraizados desloca as participantes de um fluxo conversacional difuso para um empenho coletivo de buscar definições, explicar situações e posicionar-se diante delas. Consideramos que esse momento de politização é um dos traços que caracterizam a discussão política. Ele traz ganhos para o processo deliberativo, na medida em que um público, localizado fora do fluxo principal de discussão política, procura entender e produzir sentido acerca de diferentes discursos que lhes dizem respeito (MARQUES, 2006). Muitas vezes, os contrapúblicos reúnem fragmentos de discursos hegemônicos e fazem diversos entrecruzamentos que alteram o encadeamento de causalidades, reconstroem representações e subvertem juízos morais sobre a própria condição

10 Esse termo é utilizado por Nancy Fraser (1992) ao propor um modelo de rede dispersa e ramificada de públicos, com o intuito de acomodar os desejos das mulheres e de outros grupos excluídos originados em seus próprios espaços, e elaborados em seus próprios termos. Para esses "contrapúblicos subalternos" os limites entre o público e o privado, por exemplo, podem ser renegociados, repensados, desafiados e reformulados. 
(WEST \& GASTIL, 2004). O trecho abaixo transcrito ${ }^{11}$ revela como as beneficiárias do Bolsa-Família reagem a diferentes discursos sobre temas pejorativos relacionados a elas:

Cibele: Eles [os políticos] têm mania de falá que o povo brasileiro é acomodado. Não é o povo brasileiro... Os pobres, eles falam que são acomodados. Não é isso, mas é que eles tão cansados de tanta palhaçada, porque lutam, lutam e não conseguem nada. Sai um benefício, você corre atrás e passa a maior humilhação pra pegá...

Alda: É uma humilhação. Quando eu fui fazê o cadastro, cheguei lá 7 horas da manhã e só fui atendida às 3 da tarde. Quer dizer, é uma coisa assim, muito humilhante pra ganhá 15 reais [7 dólares].

Cibele: Se não precisasse, ia passá por uma humilhação dessas?

Alda: Sem contá a briga que teve na porta. As pessoas querendo cortá a fila. [...] Aí sai aquela confusão, aí sai na televisão, como se as pessoas pobres fossem qualquer marginal, como um lixo, como qualquer zé-ninguém...

Brígida: Aí eles vai falá o quê? “Olha lá a favelada como é que tá lá”.

Diana: É... Gosta de fazê barraco...

Cibele: Na verdade, eles não falam assim, "a periferia", eles falam "a favela". Eles não têm nem a capacidade de tratar as pessoas com dignidade... (CRAS Norte, 12.abr.2006, Campinas).

Podemos perceber, então, que as beneficiárias identificam diferentes discursos, assim como seus principais porta-vozes, para questionar o fato de que os pobres seriam acomodados e favelados. Em um primeiro momento, os governantes são atrelados ao discurso da "acomodação". É importante notar que a maior crítica feita ao Programa Bolsa-Família é a de que ele, ao dar dinheiro para a população pobre, desestimularia a busca pelo emprego. Em um segundo momento, o grupo aciona testemunhos de "humilhação" de modo a enfrentar o estigma da "acomodação". Na verdade, as participantes não problematizam o pano de fundo moral que reproduz as condições de sua desvalorização, ou seja, elas não questionam a humilhação, mas assumem que ser humilhado faz

11 Nos trechos transcritos das discussões, respeitou-se a língua falada; não houve, portanto, adaptação à norma culta da língua (nota dos revisores). 
parte do tratamento destinado aos pobres. O terceiro discurso por elas acionado é o discurso da mídia, recheado de estereótipos pejorativos como "favelado" e "marginal" e produzido por agentes que os enquadram como "lixo" (MARQUES, 2006). O grupo tenta estabelecer a diferença entre o que entende por "periferia" (para elas, um termo positivo) e "favela" (termo ligado à criminalidade), ao mesmo tempo em que acusam os porta-vozes desses discursos - que podem ser tanto os atores midiáticos quanto a sociedade em geral - de não considerá-las dignamente.

Como ressaltam Mansbridge (1999) e Kingfisher (1996), as conversações que se processam às margens do fluxo principal de debate acerca de um tema político geram pontos de vista transformativos ao rejeitarem categorias impostas. Essa forma de resistência tem a capacidade de gerar impulsos politizados de luta contra a desvalorização. Nesse sentido, esse exercício de contrapor discursos hegemônicos e de ampla visibilidade aos seus próprios pontos de vista e experiências revela-se extremamente útil ao processo deliberativo. Essa atitude propicia, entre outros, o desenvolvimento de capacidades argumentativas, de justificação de pontos de vista e de contestação de maneiras de opressão simbólica.

\subsection{A revelação de premissas de fundo}

Em momentos de discordância entre os participantes dos grupos de discussão, é necessário que os pressupostos que formam a base dos proferimentos expressos ou das razões acionadas sejam explicitados. Frequientemente, é nesses momentos que os próprios participantes indagam-se e desafiam-se mutuamente, assumem o controle da discussão e elegem as questões que percebem como relevantes (SMITHSON, 2000). A explicitação de premissas, por demandar um exercício de justificação recíproca acerca de questões coletivas, confere densidade ao fluxo conversacional, politizando-o. No escopo de nossa investigação empírica, a questão de gênero mostra-se frequientemente como um elemento politizador das discussões. A relação que se estabelece entre a perpetuação da pobreza e o aumento do número de filhos, e entre a gravidez na adolescência e a interrupção quase "sem volta" da trajetória de inserção econômica 
da mulher, aponta questões que indicam a vivência da sexualidade feminina como elemento integrante do pano de fundo moral responsável pela reprodução de desigualdades e de injustiças materiais.

Assim, quando indagadas sobre a existência de possibilidades de saírem da pobreza, as participantes de um dos grupos de discussão escolheram a oposição "trabalho" versus "namoro" para explicitarem suas posições:

Marta: Prá sair da pobreza eu tenho experiência pela minha família. Sabe como faz? Estudá muito e fazê curso. Consegue sair da pobreza, sim. [...] E depois, namorá também... Minha família falava: "Não arruma qualquer namorado, não. Primeiro cê estuda, cê trabalha, cê faz curso, cê faz tudo".

Maria: Olha só procê vê, igual ocê falou, é oportunidade. Se minha mãe tivesse condição de pagá um curso pra mim, eu acredito que até meus irmãos, eles iam pagá, porque sabem da minha capacidade de chegar lá.

[...]

Marta: Sabe por quê? A gente não tem essa oportunidade, então depois começa a pensar em namorado. É isso que acontece.

[Falam todas juntas, algumas discordam]

Carla: Não, não e não!

Marta: Começa a pensar em namorado, depois que tem filho, aí pronto, acabou! Acaba com a tranquiilidade da gente. [...] Tem muita gente que sai da favela. Mas por que eles sai da favela? Porque eles só pensam no estudo e no trabalho. Porque eu acho que depois que a gente só pensa em namorar, a gente só quer namorar... $[\ldots]$

Maria: Eu acho que, tipo assim, se você tem uma meta na sua vida, [...] não é um namorado que vai te atrapalhar, até porque se ele não for compreensivo...

Lúcia: Chute na bunda dele...

Maria: A minha meta é estudar e trabalhar? Concordo. [...] Muitos namorados que eu conheço ajuda a namorada a estudá. Não é só isso, estudar e trabalhar... A vida não é só isso.

Marta: Mas porque nem todo mundo pensa igual. As pessoas às vezes pensam em namorar... (Regional Venda Nova, 31.out.2005, Belo Horizonte). 
O argumento de que "namorar atrapalha o projeto de sair da pobreza" foi questionado pela maioria das participantes, constrangendo a participante Marta a mobilizar as premissas que fundamentavam suas razões. Para grande parte delas, dissociar a sexualidade da dimensão econômica da ascensão social era fundamental. A discussão passou a estruturar-se em torno da seguinte questão: para que a mulher supere a pobreza é preciso abdicar de sua afetividade e de seu desejo? No decorrer da troca de argumentos, foi possível evidenciar que o potencial de contradição, desacordo e conflito latente nas conversações não só foi revelado, como também explorado de maneira reflexiva pelas participantes, apontando, inclusive, outro aspecto geralmente associado às discussões políticas.

A evocação de exemplos e histórias pessoais, passadas ou de "destinos coletivos" é, segundo Duchesne e Haegel (2004, p. 891), "o procedimento que observamos com mais frequiência no processo de implicação dos participantes na discussão, sendo que o acordo ou a contestação de sua dimensão exemplar constitui o essencial do trabalho de conflitualização". Para Robert Goodin (2006), as crenças e posições das pessoas são sustentadas por razões, sendo que é a ação de desvelar as razões e premissas por trás dos argumentos a principal contribuição das conversações e discussões para o processo deliberativo. Assim, a dinâmica de explicitação de premissas e razões não deve visar o reconhecimento de um certo participante como aquele que tem razão, mas como aquele capaz de prover razões capazes de sustentar seus argumentos diante das indagações colocadas pelos demais participantes.

\subsection{A identificação de questões sensíveis}

Pesquisas desenvolvidas por Gamson (1992); Bennett et alii (2000); Wyatt, Katz e Kim (2000) e Conover, Searing e Crewe (2002) revelam que as pessoas preferem engajar-se em discussões privadas. Os motivos dessa escolha variam. Um primeiro motivo refere-se ao fato de que os espaços privados oferecem um acesso mais fácil às questões em debate. Aliada a isso, há uma pequena probabilidade de que desigualdades de recursos e de capacidades comunicativas básicas atrapalhem a participação das pessoas. Mas, como apontam 
Conover, Searing e Crewe (2002, p. 57), o principal motivo é que as discussões privadas são percebidas como mais seguras do que as públicas, uma vez que "são mais resistentes aos aspectos perigosos da contestação. [...] Optar pela discussão privada significa proteger a privacidade de preferências e identidades".

Os grupos de discussão dão forma a um contexto de exposição pública da individualidade. Segundo Deborah Warr (2005, p. 202), "em um grupo de discussão, os participantes são convidados a falar para uma audiência. Muitos não estão acostumados a esse cenário, mesmo quando outros participantes são vistos como semelhantes ou como interlocutores confiáveis”. Assim, os participantes, ao dirigirem-se uns aos outros, partem geralmente de princípios básicos como a confiança mútua, o senso comum na escolha das palavras e expressões, ou seja, procuram acionar um pano de fundo compartilhado sobre o lugar a elas destinado socialmente. Em situações de conversação, a confiança e a cordialidade imperam como condições de proteção individual contra possíveis agressões à própria identidade. Entretanto, quando questões sensíveis (WARREN, 2006) entremeiam essas situações, as pessoas se vêem diante da exposição pública de suas fragilidades. Tal aspecto pode ter dois tipos de implicação para a politização da conversação. O primeiro refere-se ao repúdio ao conflito e à afirmação da premissa da confiança. O segundo trata da capacidade dos interlocutores de assumirem o risco de enfrentar constrangimentos envolvendo-se em um debate em que assumem e defendem suas posições. Essas implicações foram avaliadas nas seções seguintes. No momento, detemo-nos na identificação de como essas questões apareciam para as beneficiárias.

No trecho seguinte, podemos observar como o fato de ter "pouco estudo" prejudicava não só o auto-entendimento das participantes, como também se colocava como obstáculo para a obtenção da estima social (HONNETH, 1995; ANDERSON \& HONNETH, 2005):

Rute: Eu acho que se a gente arruma um serviço, tem como sair da pobreza. Mas é difícil, né, porque a gente tem que cuidar dos filhos e não tem com quem deixá eles... O estudo também é pouco... 
Judite: É igual ela falou, a gente quer trabalhar, mas como? A gente tem que ficá em casa e cuidá dos filhos e, muitas vezes, como ela, ela tá parada, eu também tô desempregada... Quer dizer, você quer ter um emprego, você quer mudar de vida, você quer fazer alguma coisa, mas não surge a oportunidade...

Rute: É. E, às vezes, a gente pensa assim "será que eu vou conseguir?", "Será que eu sou capaz?".

Heloísa: Eu mesma acho que não sou, porque eu não sei ler. Quando eu ia caçá emprego, eu chorava, porque eu gosto de trabalhar, mas porque eu não tenho leitura, ninguém me dava. Eu me sinto assim, inútil, sabe, de ficá em casa... (CRAS Sul, 13.jul.2006, Campinas).

A oposição "mãe" versus "trabalhadora" instaurou uma questão sensível justamente porque as dificuldades em conseguir um emprego expuseram as deficiências e as identidades dessas "mães, pobres, desempregadas e sem estudo" ao escrutínio público. Isso tornou a discussão um empreendimento perigoso e ameaçador. Muitas vezes, não é a ausência de reconhecimento que impede as pessoas de se implicarem em questões sensíveis, mas o próprio medo de serem associadas a uma posição degradante. Novamente, a questão do gênero foi tematizada pelas participantes como um obstáculo à formação de sua autonomia e da superação da precariedade.

A observação de como os participantes da discussão comportavam-se diante de questões que expunham suas identidades é de fundamental relevância para processos deliberativos que envolvem indivíduos e grupos profundamente marcados por opressões econômicas e simbólicas. Afinal, o modo como elas viam-se inseridas no universo do trabalho e o modo como lidavam com o próprio entendimento ao apresentar-se diante do outro possuíam relevantes implicações não só para a construção de identidades individuais e coletivas, mas também para o questionamento de desigualdades de ordem material.

\subsection{Assumir o risco do debate}

No contexto dos grupos de discussão, o esforço das participantes para descrever e explicar aspectos das próprias vivências encontrava muitos obstáculos. Um deles apresentou-se sob a forma do "risco" trazido pelo ato de expor um ponto de vista diante dos 
outros. Para Duchesne e Haegel (2004), "correr um risco" configurase em uma aposta necessária, uma vez que os interlocutores não podem saber, a priori, quando seu ponto de vista não será acolhido pelos outros, transformando-se na causa de um conflito. $\mathrm{O}$ trecho abaixo evidencia o exato momento em que uma participante do grupo de discussão assumiu o risco de expressar, ainda que de maneira insegura, uma opinião sobre a qual não tinha certeza acerca do posicionamento dos demais:

Moderadora: Quem critica o Lula diz que o Bolsa-Família é uma esmola.

Cida: Eu acho... Êpa, vou falar, é quase uma esmola, né, o BolsaFamília? Ele [o Lula] acha que se tivesse um emprego a gente dependia do emprego e não era... Não precisava de uma esmola, não é verdade?

Jane: É porque se você sabe que tem um dinheiro pra recebê, cê não vai se esforçar pra trabalhar...

Eunice: Mas se a gente fala que o Bolsa-Família é esmola, fica parecendo que quem recebe é esmolento...

Moderadora: Vocês se sentem assim?

[Todas negam.]

Ivone: Não, eu não se sinto assim, não. Pra mim, não é esmola. Na minha opinião é uma ajuda.

Cida: É uma ajuda boa. E mesmo que fosse esmola, é uma esmola boa, porque tira muita gente do fundo do poço.

Zilda: É. Mas não é esmola, não.

Cida: Que seja esmola ou não, não teve um governo que fez o que o Lula tá fazendo. Eu não sei se vocês concordam comigo... (CRAS Sudoeste, 17.ago.2006, Campinas).

A associação entre o Bolsa-Família e a esmola é um tema que sempre suscitou uma maior implicação dos participantes dos grupos de discussão. Nesse caso, a participante Cida, ao tentar elaborar seu ponto de vista, hesitou num primeiro instante. Após uma pausa, ela diz: "Êpa, vou falar". Nesse momento, ainda que de modo inseguro, ela assumiu o risco de afirmar a associação entre o benefício e uma esmola. Como Cida lançou seu posicionamento em forma de pergunta 
dirigida ao grupo, as demais participantes se sentiram compelidas a se manifestar. A participante Jane mobilizou o discurso da "acomodação", enquanto que Eunice contestou a associação, por acarretar o título de "esmolento" para aquele que recebe o benefício. A partir de então, cada participante procurou resguardar o próprio ponto de vista - o que pode ser evidenciado pelo uso de expressões como: "na minha opinião" -, evitando assim um confronto mais direto. O grupo oscilava entre caracterizar o Programa como esmola ou ajuda. Diante do impasse, Cida buscou gerar um acordo em torno das "boas ações de Lula" para com a população "mais humilde". Esse ponto revelou-se previamente como consenso entre as participantes. Assim, quando Cida o acionou e disse: "não sei se vocês concordam comigo", ela já sabia da existência de um background de concordância.

A tentativa de Cida para buscar um consenso no grupo expressa a dificuldade de desdobramento de um debate em contextos marcados pela ordem do apoio recíproco e da confiança. Todavia, é possível ressaltar a importância da produção coletiva do entendimento e dos argumentos dispostos diante do outro. Assumir o risco do debate, mesmo que o confronto não se desdobre, deve ser visto como um desafio necessário à politização dos pontos de vista. O fato de os participantes se perceberem em uma situação de risco e, mesmo assim, optar pela verbalização de suas opiniões acarreta um relevante ganho para o processo deliberativo.

\subsection{Não correr o risco}

Correr ou não o risco imposto pelo debate instaurou momentos sensíveis na discussão do grupo. Defender explicitamente uma posição diante dos interlocutores acarretou consequiências que foram desde a ruptura de laços de amizade ou de solidariedade até a pressão de transformar as próprias preferências e a natureza de sua identidade (CONOVER, SEARING \& CREWE, 2002; DUCHESNE \& HAEGEL, 2004). Por isso, os participantes evitavam assumir posições alegando o caráter privado das opiniões. O risco de ter que defendêlas ou justificá-las publicamente parecia ser entendido com uma invasão de privacidade. $\mathrm{O}$ trecho abaixo transcrito evidencia como a participante Ana mantinha-se cautelosa diante do argumento de 
que a "Bolsa-Família é uma esmola", sustentado pela participante Hilda. Era visível o modo como Ana evitou implicar-se na discussão, exigindo que a moderadora interferisse várias vezes para tentar desdobrar o conflito instaurado:

Ana: O governo tá respeitando as pessoas quando ele fez isso aí. Eu sei que é pouco, mas ele tá dando uma oportunidade. Não tô falando que o governo é maravilhoso. Na minha opinião, ajuda, porque o pobre era um zero à esquerda. Tudo bem, [os representantes políticos] tem que dá emprego, e dar também mais ajuda, porque com a ajuda você vai caminhar para o emprego. Você estudando ou fazendo um curso, a pessoa vai entrar na sociedade, porque ela teve uma ajuda.

Moderadora: Como é entrar para a sociedade?

Ana: Quem mora na favela... Lá fora a gente é qualquer pessoa...

Hilda: Eles acham que a gente não é pessoa de bem.

Ana: Mas quem mora aqui são pessoas honestas, trabalhadeiras. E é isso que eu quero me sentir, uma pessoa esforçada, cumpridora dos deveres.

Moderadora: E o Bolsa-Família faz vocês se sentirem assim, valorizadas?

Hilda: Não, eu não acho, porque chega a ser uma humilhação, uma esmola. Eu acho que o governo deveria dar dignidade, porque se nós temos um emprego decente, nós temos dignidade.

Moderadora: Mas o que a Ana falou é que o Bolsa-Família ajuda a caminhar para o emprego. Nesse sentido não ajuda?

Hilda: Não. Seria uma oportunidade se oferecessem cursos sem a gente ter que escolher entre nós e os nossos filhos, porque se eu voltar a estudar, por exemplo, eu vou precisar de um caderno. Mas aí, se eu comprar pra mim, eu vô tirar dos meus filhos, e aí? Eu concordo com a V. que a gente pode ter uma ajuda, um apoio para chegar na oportunidade.

[As outras participantes ficam em silêncio e algumas fazem expressões de reprovação]

Moderadora: Alguém concorda com a Hilda?

Dilma: Olha, pra alguns o Bolsa-Família pode ser esmola, mas pra outros não, porque tem umas famílias que ninguém tem condição de trabalhá, né? Uns tem criança pequena pra cuidá, e não tem creche pra todos. Eu acho que é uma ajuda (NAF Leste, 22.mar.2006, Belo Horizonte). 
A situação da conversação revelou que todo o restante do grupo discordava do posicionamento de Hilda. Mas essa discordância implícita só pôde ser identificada por meio de indicadores como: o silenciamento do grupo, os comentários paralelos em tom de cochicho com a participante mais próxima, as expressões de desagrado e os olhares de reprovação.

A discussão nesse grupo, especificamente, foi retomada no dia seguinte. Essa nova reunião do grupo forneceu uma oportunidade de investigar os motivos pelos quais a maioria das participantes não assumiu o risco do conflito com a participante Hilda. É importante mencionar que Hilda não pôde comparecer a esse segundo encontro, e, provavelmente, as participantes do grupo sentiram-se mais à vontade para manifestarem-se e estender os elementos do conflito iniciado no dia anterior:

Moderadora: Ontem a Hilda disse que a Bolsa-Família é uma esmola, uma humilhação...

Sônia: O que ela falou eu nem respondi...

Kátia: Não é esmola...

Ana: Vamos supor, sua família tá ganhando e o pai tá doente, a mãe tá doente... Tá sendo humilhado? Não, tá sendo ajudado, porque as pessoas não agüentam trabalhar. Ontem eu ia falá isso, mas eu pensei "eu vô ficá calada, porque a polêmica tá demais, então eu sei a hora de eu falá". Igual eu, por exemplo, sou aposentada por invalidez. Como eu posso sair procurando emprego? Então, eu ia falá muitas coisas, mas eu não falei... Era muita coisa pra poder ser falada... Mas agora eu solto tudo (NAF Leste, 22.mar.2006, Belo Horizonte).

A ausência de Hilda pode ser percebida como o retorno de um contexto em que todas pensavam de maneira semelhante e, por isso, podiam expor suas razões de modo menos defensivo. Ana comentou que evitou a polêmica porque aquela não era uma boa hora para ela falar. Contudo, diante de suas amigas (as mulheres que participaram no segundo dia frequientavam a Oficina de Mulheres do NAF, em que faziam artesanato, mas também desenvolviam vínculos de solidariedade), ela alegou estar disposta a "soltar tudo". A hora de falar pode ser traduzida como o momento propício para expormo-nos diante daqueles em quem confiamos. $\mathrm{O}$ argumento 
que Ana iria acionar no dia anterior para contradizer Hilda exigia o reconhecimento de sua "invalidez" e inabilidade para o trabalho. Nesse sentido, Ana argumentava que o Bolsa-Família não era uma esmola, uma vez que sustentar o contrário implicaria que ela assumisse, na frente de todos, sua incapacidade.

Como vimos, justificar um ponto de vista muitas vezes requer o acionamento de experiências pessoais ligadas à própria identidade. Assim, quando um momento sensível de discordância se delineia no grupo, os participantes podem também ver-se diante de questões sensíveis. A necessidade de não ser ofendido, de reduzir os riscos de danos à própria identidade, de evitar julgamentos negativos leva os participantes a se absterem de manifestar suas opiniões.

Quando o conflito deixa de ser latente, as consequientes estratégias de implicação e não-implicação dos participantes constituem um espaço discursivo relacional no qual é possível colocar em prática a reciprocidade e o respeito mútuo com relação às preferências e argumentos sustentados por cada participante. Como sabemos, a disputa entre enquadramentos de sentido que embasam as razões e argumentos constitui-se em uma prática essencial ao processo deliberativo.

\section{Considerações finais}

As considerações e análises presentes neste trabalho enfatizam o quanto a conversação e a discussão pública são processos importantes não só para a produção e a reprodução dos significados na vida cotidiana, como também para a formação de cidadãos reflexivos e críticos, passíveis de ocuparem espaços no processo deliberativo ampliado. Nosso ambiente interativo fundamental é o das conversações. Entre elas, contudo, podemos estabelecer diferentes distinções em plataformas ligadas a atividades políticas. Conversações sociáveis, fluidas e desfocadas têm relevância social na medida em que reforçam vínculos de solidariedade e pertencimento. Essas conversações são também cívicas, uma vez que auxiliam os cidadãos a melhor interpretarem seus problemas, necessidades e situações. Conversações desse tipo processam-se em contextos comunicativos de interação cotidiana marcados pela informalidade. Outro tipo de conversação estabelece-se quando os cidadãos mu- 
dam de um nível discursivo "ingênuo" para um nível discursivo de reflexão e crítica (HABERMAS, 1997). Esse segundo nível opera com trocas de argumentos acerca de um problema definido visando a soluções ou compreensões alternativas. Diante disso, quanto mais especializadas forem as conversações, maiores serão as chances de que cidadãos e grupos sejam excluídos de processos deliberativos. A conversação informal sobre temas políticos produzida por cidadãos marginalizados, por apresentar-se desestruturada e não-direcionada à produção de decisões, é geralmente descartada como aquela capaz de beneficiar processos deliberativos.

As análises aqui desenvolvidas revelam que não podemos afirmar que somente as discussões políticas são úteis aos processos cooperativos de processamento de problemas públicos. Também as conversações que se estabelecem em espaços do cotidiano auxiliam os cidadãos a exercitarem-se comunicativamente para assumirem os riscos do debate público. Afirmar que tanto as conversações em contextos cotidianos quanto as discussões políticas contribuem para a ampla deliberação significa adotar uma definição de política que abrange também a luta cotidiana pela sobrevivência e desafiar as relações de poder existentes em nossa sociedade. Afinal, o poder comunicativo não se origina somente nas ações de públicos politicamente orientados e organizados, mas também dos cidadãos comuns, invisíveis e pobres politicamente.

Apesar de as conversações e discussões ocorrerem com maior frequiência no contexto privado e de serem pouco abertas à contestação e ao uso da razão pública, não podemos desconsiderar seu valor deliberativo. Principalmente porque, como apontam alguns teóricos deliberativos (YOUNG, 1996; HABERMAS, 1997; MANSBRIDGE, 1999), a discussão privada é uma precondição necessária para a discussão pública. Apesar de Habermas (2006, p. 415) reconhecer que as conversações entre os cidadãos na vida cotidiana levam a processos de aprendizado e de fortalecimento das capacidades comunicativas e políticas, ele não revela como os cidadãos comuns, politicamente dispersos e desorganizados (ao contrário da sociedade civil, organizada em movimentos sociais, associações e entidades politicamente fortalecidas), podem tomar parte no amplo processo de deliberação pública. 
Para responder a esse ponto, mostramos, por meio da realização de grupos de discussão com beneficiárias do Bolsa-Família, que os contextos rotineiros de conversação das pessoas revelam um tipo de cidadania construída cotidianamente, e não só em momentos específicos (como as eleições ou protestos públicos) ou em arenas institucionais formais (SCHEUFELE, 2000). Esse tipo de conexão entre as conversações informais e as discussões que envolvem questões que "devem ser discutidas por todos" (MANSBRIDGE, 1999) demonstra que os cidadãos comuns possuem uma orientação política interna, "um sentimento de que estão qualificados para lidar com questões políticas, que os dota da autoconfiança necessária para dele tomar parte" (cf. SEARING et alii, 2004, p. 10). Se assim é, poderíamos perguntarmo-nos por que os pobres brasileiros, sobretudo as mulheres, ainda continuam excluídos dos processos de deliberação pública?

Uma primeira hipótese aponta para o não-questionamento de um pano de fundo moral que estabelece critérios de classificação das pessoas de acordo, principalmente, com seu status social e econômico. O pobre, por não ter trabalho, não gerar renda e não ter oportunidades de desenvolver suas capacidades, é considerado inútil economicamente e inapto politicamente. Uma segunda hipótese refere-se, especificamente, à condição da mulher na sociedade brasileira. O Bolsa-Família, ao fazer o cartão em nome da mulher e ao reafirmar a figura materna como capaz de qualquer sacrifício em prol dos filhos, reifica a armadilha que as conduz, de modo inquestionável, a reforçar sua baixa auto-estima e sua posição subordinada. Finalmente, uma terceira hipótese liga-se à quantidade e à qualidade das conversações e discussões políticas produzidas por essas pessoas. Nem todas as conversações geram momentos de politização responsáveis pelo desenvolvimento das habilidades cívicas e pela socialização política dessas pessoas.

Não obstante, o presente trabalho demonstra que as conversações e discussões políticas em grupo a respeito de temas específicos em contextos rotineiros de comunicação podem promover efeitos ou ganhos atribuídos a processos deliberativos ideais. Citamos, aqui, o poder educativo (aperfeiçoamento das qualidades morais, práticas e cognitivas); o poder de gerar sentimento de comunidade e vínculos de solidariedade; a produção de entendimentos e soluções de maneira 
cooperativa, não-coercitiva e racional; a formação de cidadãos politicamente autônomos (capazes de desenvolver e defender os próprios argumentos diante dos outros); o respeito mútuo e a reciprocidade (COOKE, 2000; BURKHALTER, GASTIL \& KELSHAW, 2002).

Podemos afirmar, assim, que as conversações em espaços do cotidiano possibilitam oportunidades de expor pontos de vista e refletir sobre as próprias necessidades, promovendo a qualidade das opiniões, a troca recíproca de argumentos e a construção de cidadãos capazes de produzir entendimentos de modo conjunto e reflexivo sobre o universo ampliado da política.

Recebido em 4.6.2007 Aprovado em 18.2.2008

\section{Referências bibliográficas}

ANDERSON, J. \& HONNETH, A. Autonomy, Vulnerability, Recognition, and Justice. In: CHRISTMAN, J. \& ANDERSON, J. (eds.). Autonomy and the Challenges to Liberalism: New Essays. Cambridge: Cambridge University, 2005.

BENNETT, S.; FLICKINGER, R. \& RHINE, S. Political Talk over Here, over There, over Time. British Journal of Political Science, v. 30, p. 99-119, 2000.

BERTRAND, J.; BROWN, J. \& WARD, V. Techniques for Analyzing Focus Group Data. Evaluation Review, v. 16, n. 2, p. 198-209, Apr.1992.

BOHMAN, J. Public Deliberation: Pluralism, Complexity, and Democracy. Boston: MIT, 1996.

. Deliberative Democracy and Effective Social Freedom: Capabilities, Resources, and Opportunities. In: BOHMAN, J. \& REHG, W. (eds.). Deliberative Democracy: Essays on Reason and Politics. Cambridge: MIT, 1997.

BRYMAN, A. Focus Groups. In: BRYMAN, A. Social Research Methods. Oxford: Oxford University, 2001.

BURKHALTER, S.; GASTIL, J. \& KELSHAW, T. A Conceptual Definition and Theoretical Model of Public Deliberation in Small Face-to-Face Groups. Communication Theory, v. 12, n. 4, p. 398-422, Nov.2002. 
CAREY, M. A. The Group Effect in Focus Groups: Planning, Implementing, and Interpreting Focus Groups Research. In: MORSE, J. (ed.). Critical Issues in Qualitative Research Methods. London: Sage, 1994.

CONOVER, P.; SEARING, D. \& CREWE, I. The Deliberative Potential of Political Discussion. British Journal of Political Science, v. 32, p. 21-62, 2002.

COOKE, M. Five Arguments for Deliberative Democracy. Political Studies, v. 48, p. 947-969, 2000.

DRYZEK, J. Deliberative Democracy and beyond - Liberals, Critics, Contestations. Oxford: Oxford University, 2000.

DUCHESNE, S. \& HAEGEL, F. La politisation des discussions, au croisement des logiques de specialisation et de conflictualisation. Revue Française de Science Politique, v. 54, n. 6, p. 877-909, déc.2004.

FEARON, J. D. Deliberation as Discussion. In: ELSTER, J. (ed.). Deliberative Democracy. Cambridge: Cambridge University, 1998.

FRASER, N. Rethinking the Public Sphere: a Contribution to the Critique of Actually Existing Democracy. In: CALHOUN, C. (ed.). Habermas and the Public Sphere. Cambridge, Mass.: MIT, 1992.

GAMSON, W. Talking Politics. Cambridge: Cambridge University, 1992.

GOMES, W. Transformações da política na era da comunicação de massa. São Paulo: Paulus, 2004.

GOODIN, R. Talking Politics: Perils and Promise. European Journal of Political Research, v. 45, p. 235-261, 2006.

GUTMANN, A. \& THOMPSON, D. Democratic Disagreement. In: MACEDO, S. (ed.). Deliberative Politics: Essays on Democracy and Disagreement. Oxford: Oxford University, p. 243-279, 1999.

HABERMAS, J. Direito e democracia: entre facticidade e validade. Rio de Janeiro: Tempo Brasileiro, 1997.

- Political Communication in Media Society - Does Democracy Still Enjoy an Epistemic Dimension? The Impact of Normative Theory on Empirical Research. Communication Theory, v. 16, p. 411-426, 2006. 
HENDRIKS, C. Integrated Deliberation: Reconciling Civil Society's Dual Role in Deliberative Democracy. Political Studies, v. 54, p. 486-508, 2006.

HONNETH, A. The Struggle for Recognition: the Moral Grammar of Social Conflicts. Cambridge, Mass.: MIT, 1995.

KIM, J.; WYATT, R. \& KATZ, E. News, Talk, Opinion, Participation: the Part Played by Conversation in Deliberative Democracy. Political Communication, v. 16, p. 361-385, 1999.

KINGFISHER, C. P. Women on Welfare: Conversational Sites of Acquiescence and Dissent. Discourse \& Society, v. 7, n. 4, p. 531-557, 1996.

KITZINGER, J. The Methodology of Focus Groups: the Importance of Interaction between Research Participants. Sociology of Health and Illness, v. 16, n. 1, p. 103-121, 1994.

KITZINGER, J. \& FARQUHAR, C. The Analytical Potential of Sensitive Moments in Focus Group Discussions. In: BARBOUR, R. \& KITZINGER, J. (eds.). Developing Focus Group Research: Politics, Theory and Practice. London: Sage, 1999.

LETELIER, C. L. Notas metodológicas: entre os grupos de conversação (Group Discussion) e as intervenções focalizadas (Focus Groups). Política e Trabalho, n. 12, p. 164-174, set.1996.

LUNT, P. \& LIVINGSTONE, S. Rethinking the Focus Groups in Media and Communication Research. Journal of Communication, v. 46, n. 2, p. 79-98, 1996.

MAIA, R. C. M. Dos Dilemas da Visibilidade Midiática para a Deliberação Pública. In: LEMOS, A. (org.). Mídia.br: Livro da XII Compós. Porto Alegre: Sulina, 2004.

MAIA, R. C. M. \& MARQUES, A. C. S. Cultural Production and Public Debate on "Sexual Other": the Struggle for Recognition in Brazil. Intersections - The Journal of Global Communications \& Culture, Athens, v. 2, n. 3-4, p. 59-68, Summer.2002.

MANSBRIDGE, J. Everyday Talk in Deliberative System. In: MACEDO, S. (ed.). Deliberative Politics: Essays on Democracy and Disagreement. Oxford: Oxford University, 1999. 
MARQUES, A. C. S. Dimensões da autonomia: o Programa Bolsa-Família no discurso midiático e na fala das beneficiárias. Contracampo, Niterói, v. 14, p. 126-162, 2006.

MARQUES, A. \& ROCHA, S. A produção de sentido nos contextos de recepção: em foco o grupo focal. Fronteiras, v. VIII, n. 1, p. 38-53, jan.-abr.2006.

MARQUES, A. \& MAIA, R. Dimensões da autonomia no combate à pobreza: o Programa Bolsa-Família sob a perspectiva das beneficiárias. Serviço Social e Sociedade, v. 92, p. 58-85, nov.2007.

MEYERS, G. Displaying Opinions: Topics and Disagreement in Focus Groups. Language in Society, v. 27, p. 85-111, 1998.

MORGAN, D. Focus Groups as Qualitative Research. London: Sage, 1997.

MORGAN, D. Focus Groups. Annual Review of Sociology, v. 22, p. 129-152, 1996.

MOY, P. \& GASTIL, J. Discussion Networks, Media Use and Deliberative Conversation. Political Communication, v. 23, n. 4, 2006.

MUTZ, D. \& MARTIN, P. Facilitating Communication across Lines of Political Difference: the Role of Mass Media. American Political Science Review, v. 95, n. 1, p. 97-114, Mar.2001.

NEUMAN, R.; JUST, M. \& CRIGLER, A. Common Knowledge. News and the Construction of Political Meaning. Chicago: The University of Chicago Press, 1992.

NORRIS, P. A Virtuous Circle - Political Communications in Postindustrial Societies. Cambridge: Cambridge University, 2000.

PAUGAM, S. La disqualification sociale: essai sur la nouvelle pauvreté. Paris: PUF, 1993.

PORTO, M. Muito além da informação: mídia, cidadania e o dilema democrático. São Paulo em Perspectiva, v. 12, n. 4, p. 17-25, out.dez.1998.

SCHEUFELE, D. Talk or Conversation? Dimensions of Interpersonal Discussion and Their Implications for Participatory Democracy. Journalism and Mass Communication Quarterly, v. 77, 2000. 
SCHERER-WARREN, I. A problemática da pobreza na construção de um movimento cidadão. Política \& Sociedade, Florianópolis, n. 3, p. 71-93, 2003.

SCHUDSON, M. Why Conversation is Not the Soul of Democracy. Critical Studies in Mass Communication, v. 14, p. 297-309, 1997.

SEARING, D.; CONOVER, P.; CREWE, I. \& SOLT, F. Studying Everyday Talk in the Deliberative System: Does Democratic Discussion Make Better Citizens? Paper Presented at the Conference on "Empirical Approaches to Deliberative Politics", European University Institute/ Swiss Chair, Firenze, May.21-22.2004.

SMITHSON, J. Using and Analysing Focus Groups: Limitations and Possibilities. International Journal of Social Research Methodology, v. 3, n. 2, p. 103-119, 2000.

STREICH, G. W. Constructing Multiracial Democracy: to Deliberate or Not to Deliberate? Constellations, v. 9, n. 1, p. 127-153, 2002.

TELLES, V. S. Pobreza e cidadania: figurações da questão social no Brasil moderno. In: TELLES, V. S. Direitos sociais: afinal do que se trata? Belo Horizonte: UFMG, 1999.

VAN DIJK, T. Discourse and the Denial of Racism. In: JAWORSKI, A. \& COUPLAND, N. (eds.). The Discourse Reader. London: Routledge, 1999.

WARR, D. It Was Fun... But We Don't Usually Talk about These Things. Analyzing Sociable Interactions in Focus Groups. Qualitative Inquiry, v. 11, n. 2, p. 200-225, 2005.

WARREN, M. What Should and Should Not Be Said: Deliberating Sensitive Issues. Journal of Social Philosophy, v. 37, n. 2, p. 163-181, 2006.

WEST, C. Women's Competence in Conversation. Discourse \& Society, v. 6, n. 1, p. 107-131, 1995.

WEST, M. \& GASTIL, J. Deliberation at the Margins: Participant Accounts of Face-to-Face Public Deliberation at the 1999-2000 World Trade Protests in Seatle and Prague. Qualitative Research Reports in Communication, v. 5, p. 1-7, 2004. 
WYATT, R.; KATZ, E. \& KIM, J. Bridging the Spheres: Political and Personal Conversation in Public and Private Spaces. Journal of Communication, v. 50, p. 71-92, Winter.2000.

YOUNG, I. Communication and the Other: beyond Deliberative Democracy. In: BENHABIB, S. (ed.). Democracy and Difference Contesting the Boundaries of the Political. Princeton: Princeton University, 1996. 
